\title{
Selective Separation of Light and Heavy Rare Earth Elements from the Pregnant Leach Solution of Apatite Ore with D2EHPA
}

\author{
Ariuntuya Battsengel ${ }^{*}$, Altansukh Batnasan ${ }^{2 *}$, Kazutoshi Haga², Atsushi Shibayama² \\ ${ }^{1}$ Graduate School of Engineering and Resource Science, Akita University, Akita, Japan \\ ${ }^{2}$ Graduate School of International Resource Sciences, Akita University, Akita, Japan \\ Email: *ariun_22@yahoo.com, *altansux@gipc. akita-u.ac.jp
}

How to cite this paper: Battsengel, A., Batnasan, A., Haga, K. and Shibayama, A. (2018) Selective Separation of Light and Heavy Rare Earth Elements from the Pregnant Leach Solution of Apatite Ore with D2EHPA. Journal of Minerals and Materials Characterization and Engineering, 6, 517-530.

https://doi.org/10.4236/jmmce.2018.65037

Received: June 30, 2018

Accepted: August 4, 2018

Published: August 7, 2018

Copyright $\odot 2018$ by authors and Scientific Research Publishing Inc. This work is licensed under the Creative Commons Attribution-NonCommercial International License (CC BY-NC 4.0). http://creativecommons.org/licenses/by-nc/4.0/ (c) (i) (8) Open Access

\begin{abstract}
Different separation techniques such as solvent extraction, ion exchange, and precipitation are often used for recovery of rare earth elements (REEs) from pregnant leach solutions obtained from acid leaching. Solvent extraction is generally accepted as the most appropriate commercial technology for separating REEs due to the need to be able to handle larger volumes of diluted pregnant solutions. This study focused on the development of selective separation of light and heavy REEs from the pregnant leach solution obtained from leaching of apatite ore in $1 \mathrm{M}$ sulfuric acid $\left(\mathrm{H}_{2} \mathrm{SO}_{4}\right)$ using solvent extraction. Three different commercial organophosphorus extractants (di-(2-ethylhexyl) phosphoric acid (D2EHPA), 2-ethylhexyl phosphonic acid mono-2-ethylhexyl ester (PC88A) and tributyl phosphate (TBP)), and the influences of experimental parameters such as extractant concentration, organic/aqueous phase ratio, diluent type, $\mathrm{pH}$, extraction time and stripping agent concentration were examined. Results showed that light REEs (LREEs) and heavy REEs (HREEs) in the pregnant leach solution were selectively separated with D2EHPA via a two-stage extraction process. In the first-stage of solvent extraction, $>90 \%$ of $(0.05 \mathrm{~g} / \mathrm{L})$ HREEs was extracted with $1.8 \mathrm{M}$ D2EHPA in kerosene while the vast majority ( $>95 \%)$ of LREEs was remained in raffinate. In the second-stage, $>93 \%(1.01 \mathrm{~g} / \mathrm{L})$ of LREEs was extracted from the raffinate with 1.8 M D2EHPA dissolved in kerosene at $\mathrm{pH}$ 1.6. HREEs (>95\%) and LREEs ( $>90 \%$ ) loaded with D2EHPA after the first and second-stage of extraction were stripped by $4 \mathrm{M} \mathrm{H}_{2} \mathrm{SO}_{4}$ and $1 \mathrm{M} \mathrm{H}_{2} \mathrm{SO}_{4}$ solutions, respectively. Distribution of middle rare earth elements (MREEs) was discussed through the extraction processes in this study.
\end{abstract}

\section{Keywords}

Light Rare Earth Elements, Heavy Rare Earth Elements, Solvent Extraction, 
Di-(2-ethylhexyl) Phosphoric Acid, Stripping

\section{Introduction}

The rare earth elements (REEs) are the group of seventeen chemical elements, including scandium, yttrium and the lanthanides. They are categorized into mainly two groups such as cerium sub-group ( $\mathrm{La}-\mathrm{Eu}$ ) and yttrium sub-group elements (Gd-Lu, Y). The cerium sub-group elements are relatively abundant and more strongly concentrated in the continental crust than the yttrium sub-group elements [1] [2]. The REEs are crucial ingredients in the production of magnets, phosphors, and batteries, which are becoming increasingly important in the green technologies such as hybrid vehicles and wind turbines [2] [3].

The rare earth phosphate minerals such as monazite (Ce, La, Th, Nd, $\left.\mathrm{Y}\left(\mathrm{PO}_{4}\right)\right)$, florencite $\left((\mathrm{La}, \mathrm{Ce}) \mathrm{Al}_{3}\left(\mathrm{PO}_{4}\right)(\mathrm{OH})_{6}\right)$, xenotime $\left(\mathrm{YPO}_{4}\right)$, cheralite $\left.\left((\mathrm{Ca}, \mathrm{Ce})(\mathrm{Th}, \mathrm{Ce})\left(\mathrm{PO}_{4}\right)_{2}\right)\right)$ and britholite $\left((\mathrm{Na}, \mathrm{Ce}, \mathrm{Ca})_{5}(\mathrm{OH})\left((\mathrm{PSi}) \mathrm{O}_{4}\right)_{3}\right)$ are often associated with fluorapatite. Hence, apatite can be used as an ore of REEs [6]. The treatment of apatite ores for REEs extraction commonly requires a pre-leach stage with mineral acids [2]-[10].

Hydrometallurgy is the most common chemical extraction method of separating individual rare earth oxides (REOs) from the mineral concentrates [2] [3] [4]. Basically, the differences in the properties of REEs affect the solubility of their salts, the hydrolysis of ions and the formation of complex species. The differences between their properties are exploited for recovery of individual REOs by fractional crystallization, fractional precipitation, ion exchange and solvent extraction processes. The REEs are usually recovered from leach solutions via solvent extraction followed by stripping and precipitation [11] [12] [13]. Nowadays, ion exchange is only used to obtain small quantities of high purity rare earth products for electronics or analytical applications. Solvent extraction is generally accepted as the most useful commercial technology for separating rare earth elements from leach solutions [12]-[17]. Commercially, D2EHPA, HEHEHP, Versatic 10, TBP, and Aliquat 336 have been widely used in rare earth solvent extraction processes [6] [10]. The use of cation exchangers, solvent extractants, and anion exchangers for separating REEs has been extensively studied [2] [3] [11] [12]. The extractions of REEs in chloride and nitrate media by D2EHPA and PC88A dissolved in kerosene were also studied sufficiently [14] [15] [16] [17], whereas the extraction of REEs from aqueous sulfate media has not been examined adequately.

The main aim of this study was to separate high purity LREEs and HREEs from a pregnant leach solution obtained from apatite leaching in a dilute sulfuric acid solution. To address this challenge, solvent extraction and stripping techniques were studied to optimize the best conditions for separation of LREEs and HREEs individually from the leach solution. 


\section{Experimental}

\subsection{Material and Reagents}

Apatite ore samples received from Mushgia Khudag, Mongolia were used in this study. Sulfuric acid $\left(\mathrm{H}_{2} \mathrm{SO}_{4}, 96 \%\right)$ was used to dissolve REEs from the apatite ore. Three different organophosphorus extractants have been used to extract REEs from the pregnant leach solution. The chemical and structural formulas of the organophosphorus extractants are shown in Table 1. The different concentrations $(0.1 \mathrm{M}-6 \mathrm{M})$ of sulfuric acid were prepared by diluting concentrated sulfuric acid with distilled water for stripping process. Toluene, cyclohexane and kerosene were used as diluents for the organic extractants. The sodium hydroxide $(\mathrm{NaOH})$ was used to adjust the $\mathrm{pH}$ of aqueous solutions.

\subsection{Instrumentation}

Elements in aqueous solutions obtained from acid leaching, solvent extraction, and stripping were measured using inductively coupled plasma optical emission spectrometry (ICP-OES)/SPS-5500, Ablic Inc./. Temperature and agitation speed (revolutions per minute, rpm) were controlled by an automatic multi-position magnetic stirring hot plate, HSH-6D/As One Corp/. The $\mathrm{pH}$ of the solutions was measured by /LAQUA/pH meter, Horiba Scientific. A mechanical shaker [Almighty shaker AW-2, AS ONE] was used for extraction and stripping experiments. The apatite ore sample and solid residue from leaching were characterized by X-Ray diffraction (XRD, Rigaku RINT-2200 V) and X-Ray Fluorescence (XRF, ZSX Primus II, Rigaku) analysis, respectively.

\subsection{Preparation of a Pregnant Leach Solution}

A $20 \mathrm{~g}$ of pulverized apatite ore sample with particle size fraction under $150 \mu \mathrm{m}$ $\left(\mathrm{D}_{80}=119 \mu \mathrm{m}\right)$ was dissolved in $1 \mathrm{~L}$ of the dilute $\mathrm{H}_{2} \mathrm{SO}_{4}$ solution under the optimum conditions determined previously [18]. The leachate and a solid residue were separated by filtration and the solid residue was washed with distilled water. The chemical composition of the pregnant leach solution (PLS) determined by ICP-OES is shown in Table 2 .

Concentrations of total REEs, calcium $(\mathrm{Ca})$ and phosphorus $(\mathrm{P})$ as major components in the PLS are $\sim 1.2 \mathrm{~g} / \mathrm{L}, 0.58 \mathrm{~g} / \mathrm{L}$ and $0.96 \mathrm{~g} / \mathrm{L}$, respectively (Table 2 ). The initial apatite ore sample, the pregnant leach solution and the leach residue from acid leaching are shown in Figure 1.

\subsection{Solvent Extraction}

This study has highlighted the influences of extraction parameters such as the performance of different organophosphorus extractants, organic to aqueous phase ratio, contact time, type of diluents and the $\mathrm{pH}$ on the extraction of REEs from the PLS. The two-stage solvent extraction process was investigated to separate light and heavy REEs from the PLS. All experiments were performed at a room temperature $\left(22^{\circ} \mathrm{C} \pm 3^{\circ} \mathrm{C}\right)$. The prepared PLS was mixed with a specific 
Table 1. Chemicals and structural formulas of organophosphorus extractants.

\begin{tabular}{ccc}
\hline Extractants (Commercial name) & Chemical Formula & Structure \\
\hline $\begin{array}{c}\text { Di-(2-ethylhexyl) phosphoric acid } \\
\text { (D2EHPA) }\end{array}$ & $\mathrm{C}_{16} \mathrm{H}_{35} \mathrm{O}_{4} \mathrm{P}$ & \\
2-ethylhexyl phosphonic acid & & $\mathrm{C}_{8} \mathrm{H}_{17} \mathrm{O}$ \\
mono-2-ethylhexyl ester (PC88A) & $\mathrm{C}_{16} \mathrm{H}_{35} \mathrm{O}_{3} \mathrm{P}$ & $\mathrm{C}_{8} \mathrm{H}_{17} \mathrm{O}^{2}$ \\
Tributyl phosphate (TBP) & & $\mathrm{C}_{8} \mathrm{H}_{17} \mathrm{O}$ \\
& $\mathrm{C}_{12} \mathrm{H}_{27} \mathrm{O}_{4} \mathrm{P}$ & $\mathrm{C}_{4} \mathrm{H}_{9} \mathrm{O}$ \\
& & $\mathrm{C}_{4} \mathrm{H}_{9} \mathrm{O}-\mathrm{OH}=\mathrm{O}$ \\
\hline
\end{tabular}

Source: Jan Rydberg et al., 2004. Solvent Extraction Principles and Practice (2nd Edition) [11]].

Table 2. Element content in the pregnant leach solution (PLS), g/L.

\begin{tabular}{|c|c|c|c|c|c|c|c|c|c|c|c|}
\hline & & \multicolumn{10}{|c|}{ Rare Earth Elements } \\
\hline \multicolumn{6}{|c|}{ Light rare earth elements (LREE) } & \multicolumn{5}{|c|}{ Heavy rare earth elements (HREE) } & \multirow{2}{*}{$\begin{array}{c}\text { Total REE } \\
\text { TREE }\end{array}$} \\
\hline $\mathrm{La}$ & $\mathrm{Ce}$ & $\operatorname{Pr}$ & $\mathrm{Nd}$ & Sm & $\mathrm{Eu}$ & Gd & Dy & Er & $\mathrm{Yb}$ & $\mathrm{Y}$ & \\
\hline \multirow[t]{2}{*}{0.295} & 0.603 & 0.045 & 0.217 & 0.023 & 0.003 & 0.005 & 0.004 & 0.002 & 0.001 & 0.026 & 1.223 \\
\hline & & \multicolumn{10}{|c|}{ Accompanying elements (impurities) } \\
\hline $\mathrm{Ca}$ & $\mathrm{P}$ & $\mathrm{Al}$ & $\mathrm{Fe}$ & $\mathrm{Sr}$ & $\mathrm{Mg}$ & $\mathrm{Na}$ & K & - & - & - & - \\
\hline 0.584 & 0.959 & 0.027 & 0.008 & 0.034 & 0.002 & 0.032 & 0.004 & - & - & - & - \\
\hline
\end{tabular}

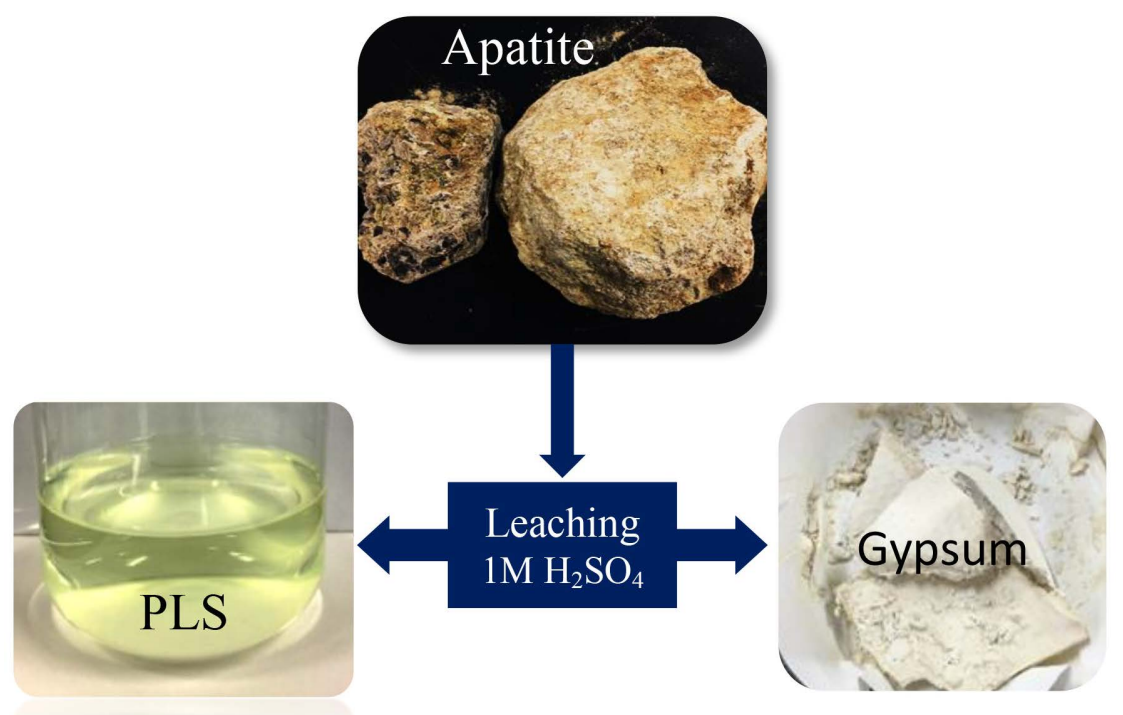

Figure 1. The pregnant leach solution obtained from apatite leaching.

volume of diluted organic extractant in a corked chemical flask and the mixture was shaken at a speed of $300 \mathrm{rpm}$ for $15 \mathrm{~min}$ to load REEs with the organic phase. Then the liquids were separated to an organic and an aqueous phase by a separatory funnel. After two-phase separation, the concentration of REEs in the aqueous phase was analyzed using ICP-OES. The REEs concentration in the or- 
ganic phase was obtained by mass balance and calculated by following equation "Equation (1)" [3];

$$
E \%=\left(C_{i n i}-C_{\text {raff }}\right) / C_{\text {ini }} * 100 \%
$$

where; $E \%$ is representing the percentage of REEs extracted into the organic phase, $C_{i n i}-\mathrm{REE}$ concentration in the PLS, $C_{\text {raff }}$-remained REEs concentration in the aqueous phase (raffinate) after extracting REEs into the organic phase. The reaction between REEs and cation exchanging extractants can be expressed as "Equation (2)". Here; (HL) $)_{2}$ is organophosphorus extractants (D2EHPA, PC88A and TBP) [2].

$$
\mathrm{REE}^{3+}+3(\mathrm{HL})_{2}=\operatorname{REE}\left(\mathrm{HL}_{2}\right)_{3}+3 \mathrm{H}^{+}
$$

The distribution coefficient $(D)$ of REEs and their separation factors $(\alpha)$ were calculated by "Equation (3) and (4)", respectively [11].

$$
\begin{aligned}
D= & \left(\left(C_{\text {ini }}-C_{\text {raff }}\right) / V_{\text {org }}\right) /\left(C_{\text {raff }} / V_{\text {aq }}\right) \\
& \alpha_{\text {HREES L LREEs }}=D_{\text {HREEs }} / D_{\text {LREEs }}
\end{aligned}
$$

where: $C_{i n i}$ and $C_{\text {raff }}$ are initial and the equilibrium concentration of REEs in the aqueous solutions, respectively. $V_{\text {org }}$ and $V_{\text {raff }}$ are the volume of organic and aqueous phase.

$\alpha_{\text {HREES LREES }}$ represents the separation factor of HREEs over LREEs. $D_{\text {HREES }}$ and $D_{\text {LREES }}$ are the distribution coefficient of heavy and light REEs into the organic on the aqueous phase.

\subsection{Stripping (Back Extraction)}

After extracting the REEs with the organic phase, different concentrations ranging from 0.5 to $6 \mathrm{M} \mathrm{H}_{2} \mathrm{SO}_{4}$ solutions were used to strip the REEs from the loaded organic phases in order to determine the best stripping conditions for LREEs and HREEs, respectively. The stripped solutions were analyzed by ICP-OES for estimation of the stripping efficiency of the REEs. The mechanism of stripping of REEs from the loaded organic phase can be expressed as "Equation (5)" [2].

$$
2 \mathrm{REE}\left(\mathrm{HL}_{2}\right)_{3}+3 \mathrm{H}_{2} \mathrm{SO}_{4}=\mathrm{REE}_{2}\left(\mathrm{SO}_{4}\right)_{3}+6(\mathrm{HL})_{2}
$$

\section{Results and Discussion}

\subsection{Extraction of Heavy REEs from the Pregnant Leach Solution}

The pregnant leach solution containing mixed REEs was used for the solvent extraction processes. The extraction efficiencies of the REEs through leaching, solvent extraction and stripping were calculated for each REE and categorized into three groups: light (La-Nd) LREEs; middle (Sm-Gd), MREEs; and heavy REEs (Dy-Y) HREEs as classified in the periodic table [1], in the following sections.

\subsubsection{Effect of Organophosphorus Extractants}

The LREEs, MREEs and HREEs in aqueous sulfuric acid media were extracted using 0.6 M concentration of D2EHPA, PC88A and TBP in kerosene, respec- 
tively. The relationship between the distribution coefficients of the REEs and extractants are shown in Figure 2. The distribution of LREEs was identical lower with the three extractants, whereas HREEs distributions were higher in D2EHPA and PC88A compared to the LREEs and MREEs. It is apparent that D2EHPA is suitable to choose as the best extracting agent for separation of HREEs from LREEs in sulfuric acid media. It has been stated that the functional group of extractants plays an important role in separating HREEs from others. Moreover, the ionic radius of REEs ions decreases with increasing the REEs atomic number [1]. Depending on the REEs' (from lanthanum to lutetium) ionic size, the bond strengths of hydrated REEs ions are varied from strongest to weakest in aqueous solution [19]. This means that heavy REEs have the weakest bond strength. It may be the case that heavy REEs were loaded first into the organic phase by D2EHPA in kerosene due to a weak bounding with water molecules in aqueous solutions.

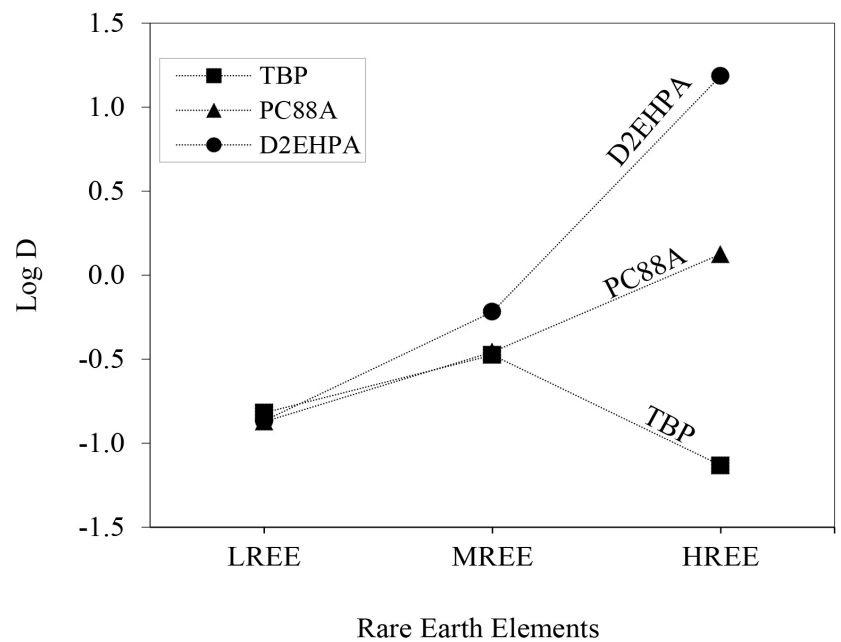

Figure 2. Effect of extractants on the separation of LREEs, MREEs and HREEs. (LREE: La, Ce, Pr, Nd; MREE: Sm, Eu, Gd; HREE: Dy, Er, $\mathrm{Yb}, \mathrm{Y}$ ). (Extractant: $0.6 \mathrm{M}$ in kerosene, $\mathrm{O} / \mathrm{A}$ ratio $=1: 2, \mathrm{pH}=1$ (initial), $300 \mathrm{rpm}$, at $22^{\circ} \mathrm{C} \pm 3^{\circ} \mathrm{C}$ for $15 \mathrm{~min}$ ).

\subsubsection{Effect of D2EHPA Concentration}

As can be seen from Figure 3, changes in concentration of D2EHPA have positively affected the HREEs extraction from the PLS.

The extractions of HREEs are increasing with an increase of the concentration of D2EHPA from 0.2 to $3.0 \mathrm{M}$. There is no significant effect on the LREEs extraction while MREEs extraction is raised slightly, when an increase in the extractant concentration. As a result, the concentration of D2EHPA was selected to be $1.8 \mathrm{M}$ for further studies due to prevention of the loss of LREEs and MREEs into the organic phase. Because the amounts of LREEs in the PLS were much higher than the HREEs. Besides that, it became complicated to separate an aqueous phase from an organic phase when the extractant concentration is increased over $2 \mathrm{M}$ due to the formation of emulsion. 


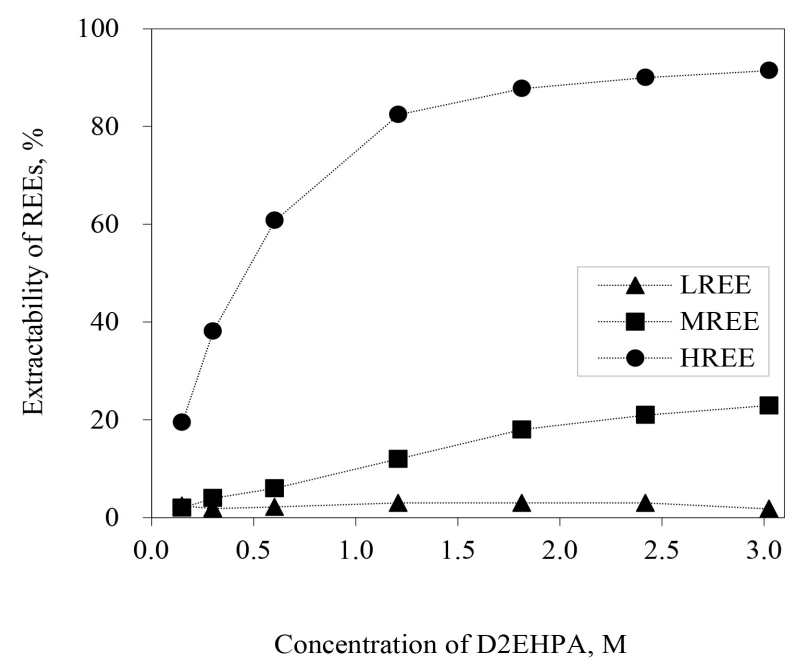

Figure 3. Effect of D2EHPA concentration. (LREE: La, Ce, Pr, Nd; MREE: Sm, Eu, Gd; HREE: Dy, Er, Yb, Y). (D2EHPA: 0.2 - 3 M, O/A ratio $=1: 2, \mathrm{pH}=1$ (initial), $300 \mathrm{rpm}$, at $22^{\circ} \mathrm{C} \pm 3^{\circ} \mathrm{C}$ for $15 \mathrm{~min}$ ).

\subsubsection{Effect of Organic to Aqueous Phase Ratio}

It is important to improve the mass transfer rate and extraction efficiency of HREEs by investigating the organic and acid $(\mathrm{O} / \mathrm{A})$ phase ratio. To find the suitable phase ratio, the extraction of the REEs from the PLS with D2EHPA was carried out using a wide range of $\mathrm{O} / \mathrm{A}$ phase ratios between 10:1 and 1:10. Figure 4 shows the increase of $\mathrm{O} / \mathrm{A}$ phase ratio gives a significant effect on the extraction of HREEs and MREEs from the PLS but it is not affecting the LREEs extraction. The extractions of HREEs and MREEs were decreased slightly and shrewdly, when the $\mathrm{O} / \mathrm{A}$ phase ratio is decreased from 10:1 to 1:10 (Figure 4). However, the O/A phase ratio of 1:3 is selected as the best extraction condition for further extraction process to remain copious amounts of LREEs and MREEs into the raffinate.

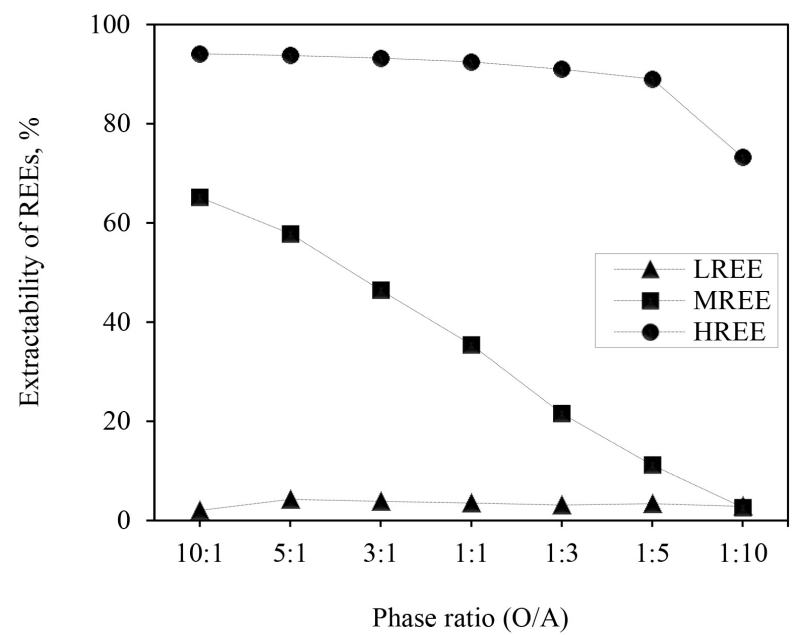

Figure 4. The effect of organic to aqueous phase ratio. (LREE: La, Ce, Pr, Nd; MREE: Sm, Eu, Gd; HREE: Dy, Er, Yb, Y). (O/A ratio $=10: 1-1: 10$, D2EHPA: $1.8 \mathrm{M}, \mathrm{pH}=1$ (initial), $300 \mathrm{rpm}$, at $22^{\circ} \mathrm{C} \pm 3^{\circ} \mathrm{C}$ for $\left.15 \mathrm{~min}\right)$. 


\subsubsection{Effect of Extraction Time}

Figure 5 shows that the trend in the extraction of all REEs from the PLS rose with an increase of the extraction/contact time from 1 to 10 minutes, whereas no significant changes have been observed in further increase of extraction time from 10 to 60 minutes. According to this result, the reaction between aqueous media and organic extractant was reached the equilibrium at $10 \mathrm{~min}$, which was selected as the best contact time for further extraction studies.

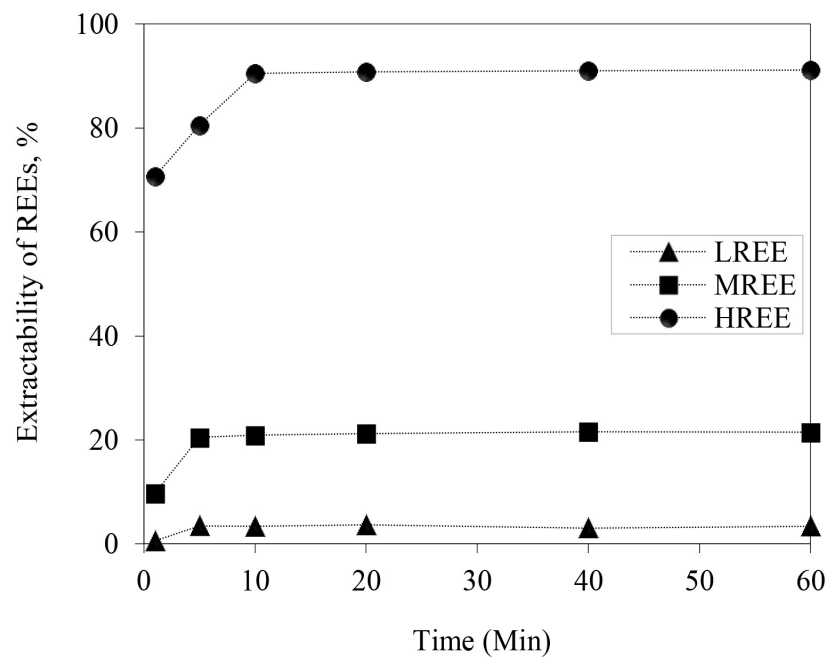

Figure 5. The effect of extraction time. (LREE: La, Ce, Pr, Nd; MREE: Sm, Eu, Gd; HREE: Dy, Er, Yb, Y). (Extraction time (1 $60 \mathrm{~min}$ ), D2EHPA: $1.8 \mathrm{M}, \mathrm{O} / \mathrm{A}=1: 2, \mathrm{pH}=1$ (initial), $300 \mathrm{rpm}$, at $22^{\circ} \mathrm{C} \pm 3^{\circ} \mathrm{C}$ ).

\subsubsection{Effect of Diluent and Separation Factor}

The distribution of REEs in D2EHPA was investigated using various diluents such as toluene, cyclohexane and kerosene, respectively. The extractabilities of LREEs, MREEs and HREEs with D2EHPA dissolved in different diluents are shown in Figure 6.

The obvious increase in the extraction of REEs with D2EHPA is observed according to the order: toluene $<$ cyclohexane $<$ kerosene. It indicates that the distribution of REEs in D2EHPA strongly depends on the nature of diluents.

The separation factors $(\alpha)$ between HREEs and LREEs were calculated at various concentrations of D2EHPA in three different diluents, respectively. It can be seen from Figure 7 that the separation factor for $\mathrm{Y}$ to Ce increases with an increase of the D2EHPA concentration from 0.6 to $1.8 \mathrm{M}$. It was also observed that the highest separation factor of 3.2 for $\mathrm{Y}$ to Ce was achieved with D2EHPA in kerosene, compared to the separation factor $(\log \alpha)$ of 2.4 and 2 for D2EHPA in toluene and cyclohexane. Hence kerosene is selected as an appropriate diluent for D2EHPA on the separation of REEs from an aqueous phase.

Consequently, the best condition for the extraction of HREEs from the pregnant leach solution obtained from apatite leaching was determined to be $1.8 \mathrm{M}$ 


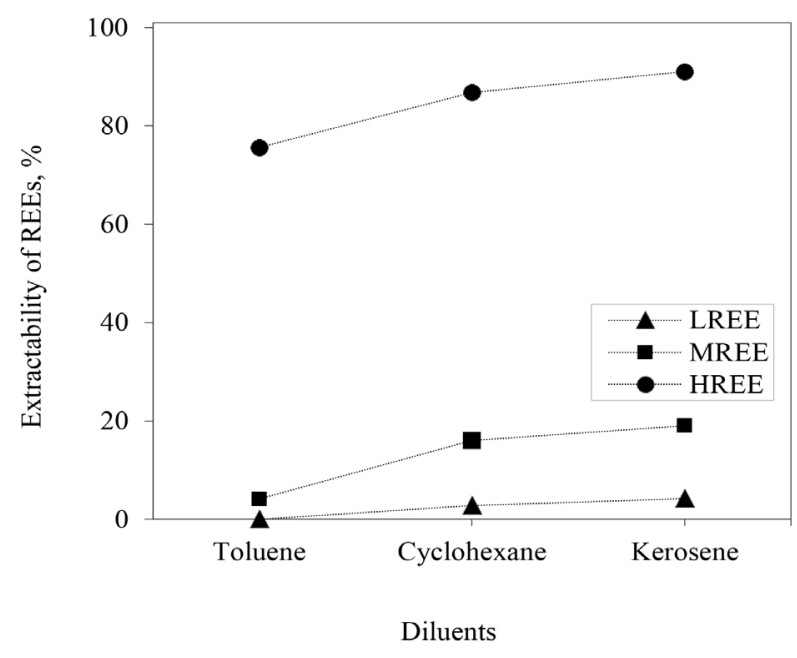

Figure 6. The effect of diluents for the extraction of REEs. (LREE: La, Ce, Pr, Nd; MREE: Sm, Eu, Gd; HREE: Dy, Er, Yb, $\mathrm{Y})$. (Diluents: toluene, cyclohexane, kerosene; D2EHPA: $1.8 \mathrm{M}$, $\left.\mathrm{O} / \mathrm{A}=1: 3, \mathrm{pH}=1,300 \mathrm{rpm}, 22^{\circ} \mathrm{C} \pm 3^{\circ} \mathrm{C}, 10 \mathrm{~min}\right)$.

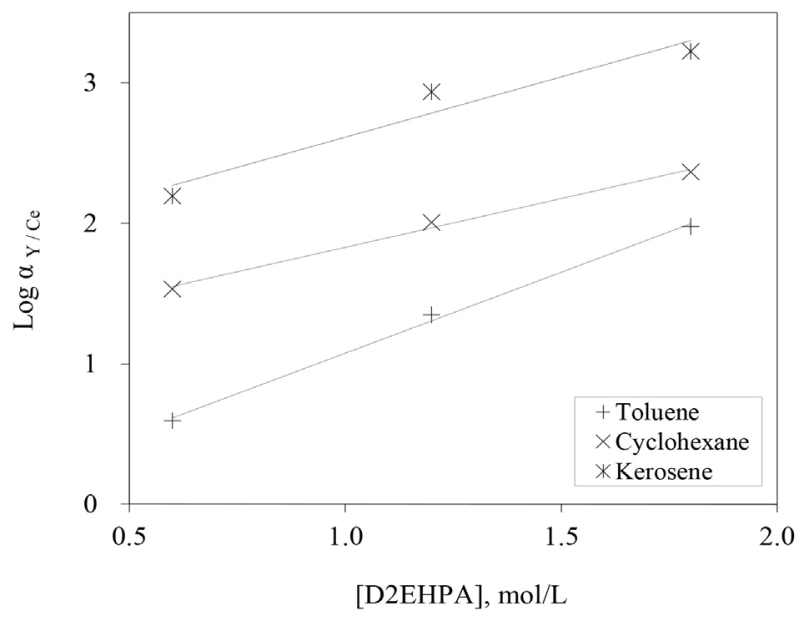

Figure 7. Separation factor of $\mathrm{Y}$ to $\mathrm{Ce}$ as a function of extractants concentrations in different diluents. (Diluents: toluene, cyclohexane, kerosene), D2EHPA 0.6 - 1.8 M, O/A = 1:3, $\mathrm{pH}=1,300$ $\mathrm{rpm}, 22^{\circ} \mathrm{C} \pm 3^{\circ} \mathrm{C}$ for $\left.10 \mathrm{~min}\right)$.

of D2EHPA in kerosene, organic to an aqueous ratio of $1: 3$, contact time of 10 min and shaking speed of $300 \mathrm{rpm}$ at a room temperature.

\subsection{Extraction of LREEs from the Raffinate (Second-Stage Extraction)}

In the batch study, proper amounts of LREEs and MREEs as well as minor amounts of HREEs remained in the raffinate were recovered by means of the second-stage solvent extraction process. The effect of $\mathrm{pH}$ and concentration of D2EHPA were examined to selectively separate the remained REEs from the raffinate. 


\subsubsection{Effect of $\mathrm{pH}$ for Extraction of REEs from the Raffinate}

The initial $\mathrm{pH}$ of the obtained pregnant leach solution was 1 that has not changed significantly after the first-stage of SX process. The $\mathrm{pH}$ of the raffinate was controlled in the range between 0 and 2 with the addition of $6 \mathrm{M} \mathrm{H}_{2} \mathrm{SO}_{4}$ and $1 \mathrm{M} \mathrm{NaOH}$, respectively. Then the extraction of REEs from the raffinate was examined under the same conditions determined in the first-stage extraction. The experimental results are summarized in Figure 8. As can be seen from Figure 8, the extraction efficiency of REEs increased with increasing the $\mathrm{pH}$. The $\mathrm{pH}$ between $1.6-1.7$ was selected as the best conditions to extract more than $80 \%$ LREEs after examining numerous experiments. The $\mathrm{pH}$ over 1.7 is avoidable because of precipitation of REEs.

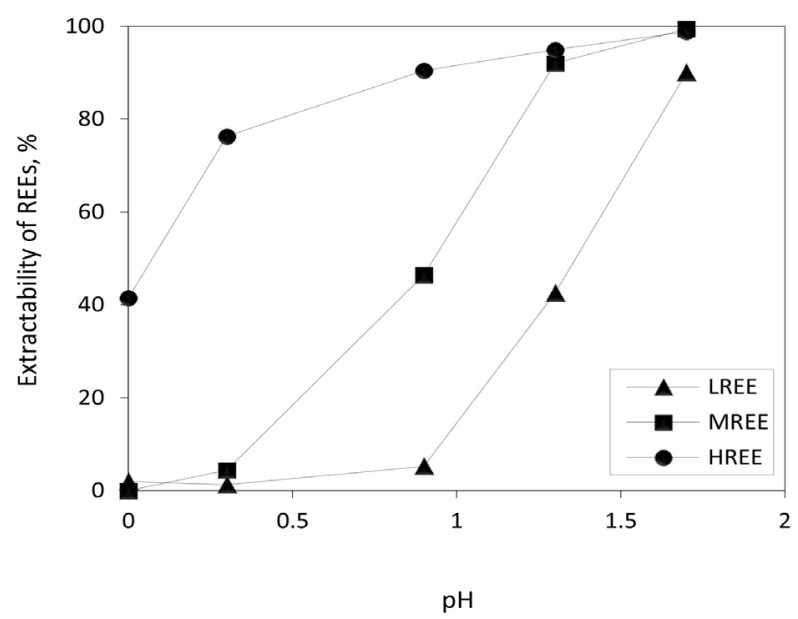

Figure 8. The effect of $\mathrm{pH}$ for the extraction of REEs from the raffinate. (LREE: La, Ce, Pr, Nd; MREE: Sm, Eu, Gd; HREE: Dy, Er, Yb, Y). $(\mathrm{pH}=(0$ - 2), D2EHPA: $1.8 \mathrm{M}, \mathrm{O} / \mathrm{A}=1: 3,300$ $\left.\mathrm{rpm}, 22^{\circ} \mathrm{C} \pm 3^{\circ} \mathrm{C}, 10 \mathrm{~min}\right)$.

\subsubsection{Effect of D2EHPA Concentration}

After determined the best $\mathrm{pH}$ condition, the second-stage extraction was conducted with the different concentrations of D2EHPA in order to examine the lower concentration of D2EHPA to reduce the consumption of extractant for recovering the remained REEs from the raffinate. The results obtained are presented in Figure 9.

Figure 9 shows that extractability of REEs reduced as the decrease of the concentration of D2EHPA from 1.8 to $0.6 \mathrm{M}$. As a result, the best extraction of REEs was achieved with $1.8 \mathrm{M}$ ofD2EHPA in kerosene. It was revealed that all REEs present in PLS can be potentially recovered at around $\mathrm{pH} 1.7$ with $1.8 \mathrm{M}$ D2EHPA at an ambient condition.

\subsection{Stripping (Back Extraction)}

The loaded organic phase from the first-stage extraction was processed in the scrub stage with $1 \mathrm{M}$ of $\mathrm{H}_{2} \mathrm{SO}_{4}$, in order to remove LREEs as impurities from the organic phase with a higher percentage of HREEs. Then a spent scrub solution 


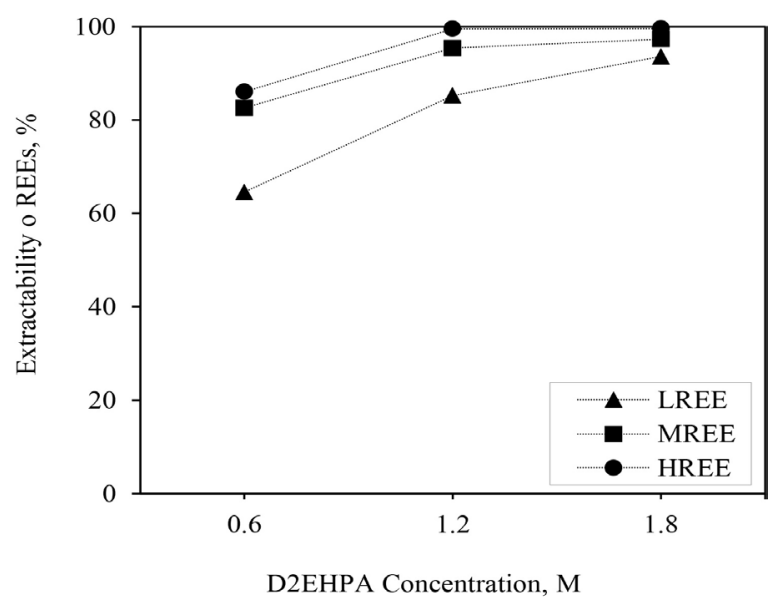

Figure 9. The effect of D2EHPA concentration for the extraction of REEs from the raffinate. (LREE: La, Ce, Pr, Nd; MREE: Sm, Eu, Gd; HREE: Dy, Er, Yb, Y). (D2EHPA concentration: $\left.0.6-1.8 \mathrm{M}, \mathrm{O} / \mathrm{A}=1: 3, \mathrm{pH}=1.7,300 \mathrm{rpm}, 22^{\circ} \mathrm{C} \pm 3^{\circ} \mathrm{C}, 10 \mathrm{~min}\right)$.

containing of LREEs was combined with the raffinate for further processing. The scrubbed organic phase containing mostly HREEs was advanced to stripping. To explore the role of acidity during the scrubbing and stripping of REEs from the organic phase in the aqueous system, experiments were performed with various $\mathrm{H}_{2} \mathrm{SO}_{4}$ concentrations ranging from $0.5-6 \mathrm{M}$. In the case of stripping, the efficiency of REEs removal increases with increasing the concentration of sulfuric acid from 0.5 to $6 \mathrm{M}$. Results showed that HREEs loaded into the organic phase after the first-stage extraction was stripped completely by $4 \mathrm{M} \mathrm{H}_{2} \mathrm{SO}_{4}$ as presented in Figure 10. Whereas the LREEs loaded into the organic phase from the second-stage extraction was effectively removed by $1 \mathrm{M} \mathrm{H}_{2} \mathrm{SO}_{4}$ (data not shown).

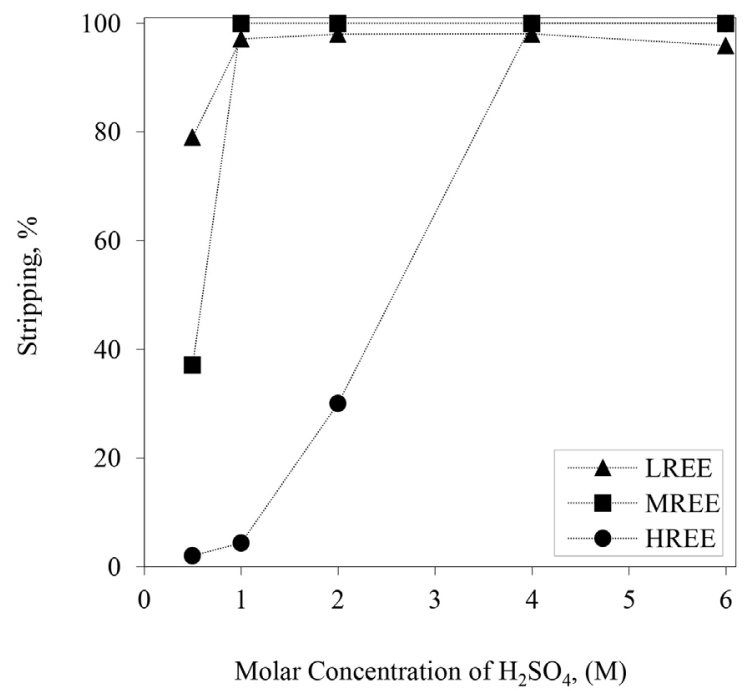

Figure 10. Stripping of REEs (LREE: La, Ce, Pr, Nd; MREE: Sm, $\mathrm{Eu}, \mathrm{Gd}$; HREE: Dy, Er, Yb, Y) from the loaded organic phase from the first-stage extraction using sulfuric acid solutions. $\left(\mathrm{H}_{2} \mathrm{SO}_{4}: 1-6 \mathrm{M}, \mathrm{O}: \mathrm{A}\right.$ ratio $\left.=1: 2,300 \mathrm{rpm}, 22^{\circ} \mathrm{C} \pm 3^{\circ} \mathrm{C}, 10 \mathrm{~min}\right)$. 
The aqueous strip solutions prepared were used for further studies on the precipitation of individual REEs. The extraction of REEs with cation exchangers is promoted by increasing the $\mathrm{pH}$ of the aqueous phase, while the stripping (reverse extraction) is elevated by increasing the acidity of an aqueous strip solution (decreasing the $\mathrm{pH}$ ) [2].

\subsection{Proposed Flowchart}

A flowsheet for the separation of LREEs and HREEs from the pregnant leach solution after apatite leaching in $1 \mathrm{M} \mathrm{H}_{2} \mathrm{SO}_{4}$ is shown in Figure 11 . The process flowsheet consists of basically three steps: 1) leaching of REEs from apatite using a dilute $\mathrm{H}_{2} \mathrm{SO}_{4} ; 2$ ) extraction of HREEs and LREEs from the pregnant leach solution and raffinate with D2EHPA; 3) stripping of the REEs from loaded organic phases into fresh aqueous solutions to extract purified LREEs and HREEs, respectively.

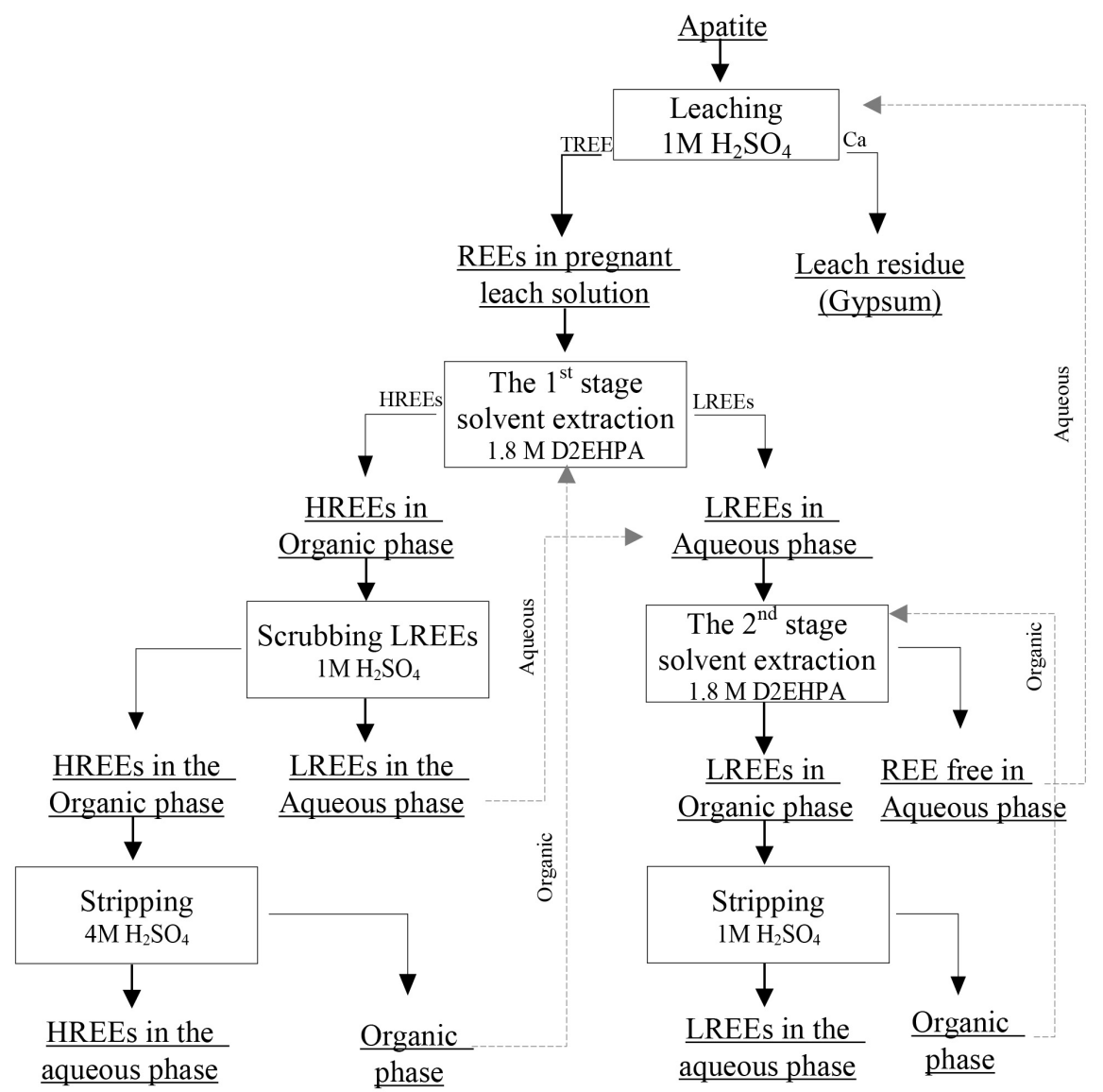

Figure 11. Proposed flowchart for the extraction of LREEs and HREEs from the pregnant leach solution after apatite leaching in $\mathrm{H}_{2} \mathrm{SO}_{4}$.

\section{Conclusion}

The two-stage solvent extraction process for recovery of REEs from the pregnant leach solution with organophosphorus acids was presented. In the first-stage extraction, over $90 \%$ of $(0.05 \mathrm{~g} / \mathrm{L})$ HREEs was separated from the PLS with $1.8 \mathrm{M}$ 
D2EHPA in kerosene and the HREEs loaded with the organic extractant were completely stripped with $4 \mathrm{M} \mathrm{H}_{2} \mathrm{SO}_{4}$. At the second-stage extraction, $1.1 \mathrm{~g} / \mathrm{L}$ LREEs present in the raffinate after the first-stage extraction were recovered with 1.8 $\mathrm{M} \mathrm{D2EHPA}$ after adjusting the $\mathrm{pH}$ of the raffinate at the $\mathrm{pH} 1.6-1.7$. As a result, 93\% (1.0 g/L) of LREEs were extracted into the organic phase. The loaded organic phase was stripped by $1 \mathrm{M} \mathrm{H}_{2} \mathrm{SO}_{4}$ and $>90 \%(0.91 \mathrm{~g} / \mathrm{L})$ LREEs were stripped back into the aqueous phase. Consequently, it can be concluded that LREEs and HREEs in the PLS can be separated into the two fractions with high efficiency and high selectivity using two-stage SX process. The results suggest a further step towards developing REE purification process. It means that individual rare earth element could be recovered from enriched light and heavy REEs solutions by separation processes.

\section{Acknowledgements}

The authors would like to thank the Leading Graduate Program of Akita University "New Frontier Leaders for Rare Metals and Resources" from Japan Society for the Promotion of Science (JSPS) and JSPS KAKENHI (Grant number: JP16K18330) for their financial support.

\section{Conflicts of Interest}

The authors declare no conflicts of interest regarding the publication of this paper.

\section{References}

[1] Henderson, P. (1984) The Book of Rare Earth Element Geochemistry. Elsevier, New York, 1-152.

[2] Krishnamurthy, N. and Gupta, C.K. (2006) Extractive Metallurgy of Rare Earths. 2nd Edition, CRC, Taylor \& Francis Group, Boca Raton, 235-332.

[3] Zhang, J., Zhao, B. and Schreiner, B. (2016) Separation Hydrometallurgy of Rare Earth Elements. Springer, Switzerland, 55-165.

https://doi.org/10.1007/978-3-319-28235-0

[4] Habashi, F. (2013) Extractive Metallurgy of Rare Earth. Canadian Metallurgical Quarterly, 52, 224-233. https://doi.org/10.1179/1879139513Y.0000000081

[5] Michael, E.F. and Yuanming, P. (1995) Site Preference of Rare Earth Elements in Fluorapatite. Journal of American Mineralogist, 80, 329-335.

https://doi.org/10.2138/am-1995-3-414

[6] Dorozhkin, S.V. (1998) Ecological Principles of Wet-Process Phosphoric Acid Technology. Journal of Chemical Technology \& Biotechnology, 71, 227-233. https://doi.org/10.1002/(SICI)1097-4660(199803)71:3<227::AID-JCTB801>3.0.CO;2 $\underline{-\mathrm{E}}$

[7] Kandil, A.T., Aly, M.M., Moussa, E.M., Kamel, A.M., Gouda, M.M. and Kouraim, M.N. (2010) Column Leaching of Lanthanides from Abu Tartur Phosphate Ore with Kinetic Study. Journal of Rare Earth, 28, 576-580. https://doi.org/10.1016/S1002-0721(09)60157-5

[8] Walawalkara, M., Nicholb, C.K. and Azimi, G. (2016) Process Investigation of the 
Acid Leaching of Rare Earth Elements from Phosphogypsum Using $\mathrm{HCl}, \mathrm{HNO}_{3}$, and $\mathrm{H}_{2} \mathrm{SO}_{4}$. Hydrometallurgy, 166, 195-204.

https://doi.org/10.1016/j.hydromet.2016.06.008

[9] Senanayake, G., Jayasekera, S., Bandara, A.M.T.S., Koenigsberger, E., Koenigsberger, L. and Kyle, J. (2016) Rare Earth Metal Ion Solubility in Sulphate-Phosphate Solutions of $\mathrm{pH}$ Range- 0.5 to 5.0 Relevant to Processing Fluorapatite Rich Concentrates: Effect of Calcium, Aluminum, Iron and Sodium Ions and Temperature up to $80^{\circ} \mathrm{C}$. Minerals Engineering, 98, 169-176.

https://doi.org/10.1016/j.mineng.2016.07.022

[10] Preston, J.S., Cole, P.M., Craig W.M. and Feather, M. (1996) The Recovery of Rare Earth Oxides from a Phosphoric Acid By-Product. Part 1: Leaching of Rare Earth Values and Recovery of a Mixed Rare Earth Oxide by Solvent Extraction. Hydrometallurgy, 41, 1-19. https://doi.org/10.1016/0304-386X(95)00051-H

[11] Rydberg, J., Cox, M., Musikas, C. and Choppin, G.R. (2004) Solvent Extraction Principles and Practice. 2nd Edition, Marcel Dekker, Inc., New York, 339-365. https://doi.org/10.1201/9780203021460

[12] Xie, F., Zhang, T., Dreisinger, D. and Doyle, F. (2015) A Critical Review on Solvent Extraction of Rare Earths from Aqueous Solutions. Journal of Minerals Engineering, 56, 10-28. https://doi.org/10.1016/j.mineng.2013.10.021

[13] Habashi, F. (1998) EPD Congress: Solvent Extraction in the Phosphate Fertilizer Industry. Journal of the Minerals, Metals \& Materials Society, 201-218.

[14] Abreu, R.D. and Morais, C.A. (2014) Study on Separation of Heavy Rare Earth Elements by Solvent Extraction with Organophosphorus Acids and Amine Reagents. Journal of Minerals Engineering, 61, 82-87. https://doi.org/10.1016/j.mineng.2014.03.015

[15] Hiskeya, J.B. and Coppb, R.G. (2018) Recovery of Yttrium and Neodymium from Copper Pregnant Leach Solutions by Solvent Extraction. Journal of Hydrometallurgy, 177, 21-26. https://doi.org/10.1016/j.hydromet.2018.02.012

[16] Wang, L., Long, Z., Huang, X., Yu, Y., Cui, D. and Zhang, G. (2010) Recovery of Rare Earths from Wet-Process Phosphoric Acid. Hydrometallurgy, 101, 41-47. https://doi.org/10.1016/j.hydromet.2009.11.017

[17] Wu, S.X., Wang, L.S., Zhang, P., El-Shall, H., Moudgil, B., Huang, X.W., Zhao, L.S., Zhang, L.F. and Feng, Z.Y. (2018) Simultaneous Recovery of Rare Earths and Uranium from Wet Process Phosphoric Acid Using Solvent Extraction with D2EHPA. Hydrometallurgy, 175, 109-116. https://doi.org/10.1016/j.hydromet.2017.10.025

[18] Battsengel, A., Narankhuu, A., Batnasan, A., Haga, K., Watanabe, Y. and Shibayama, A. (2018) Recovery of Light and Heavy Rare Earth Elements from Apatite Ore Using Sulphuric Acid Leaching, Solvent Extraction, and Precipitation. Journal of Hydrometallurgy, 179, 100-109. https://doi.org/10.1016/j.hydromet.2018.05.024

[19] Persson, I. (2010) Hydrated Metal Ions in Aqueous Solution: How Regular Are Their Structures? Pure and Applied Chemistry, 82, 1901-1917.

https://doi.org/10.1351/PAC-CON-09-10-22 